\title{
The Idea of "Third Generation Nigerian Literature": Conceptualizing Historical Change and Territorial Affiliation in the Contemporary Nigerian Novel
}

\author{
HAMISH DALLEY \\ Australian National University \\ hamish.dalley@anu.edu.au
}

\begin{abstract}
Recent critical discourse on Nigerian fiction employs historicizing techniques that categorize texts according to generations, each of which is presumed to share formal and political qualities and represent a distinct stage in national literary development. This essay critiques the prevalent "Third Generation Nigerian Literature" concept by highlighting its reliance on spatio-temporal constructs that fail to account for the complexity of the texts it classifies. Through a close reading of Adaobi Tricia Nwaubani's I Do Not Come to You by Chance (2009) and Teju Cole's Open City (2011), I show that recent Nigerian novels are shaped around ambivalent spatio-temporal imaginaries that exceed the national-generational framework. Nwaubani's novel explores characters' attempts to establish clear boundaries of ethical affiliation, while Cole's dramatizes imaginative border crossing and cosmopolitan de-centeredness. I show that both are traversed by alternative temporalities and spatialities that deconstruct their dominant frameworks. I therefore suggest that this ambivalence should prompt us to reflect on how our analyses of "Third Generation Nigerian Literature" could be enriched by exploring more multilayered methods of historicization beyond the nation-generational approach.
\end{abstract}

I

n the past ten years it has become common to categorize contemporary Nigerian writing as belonging to a "third generation," a more or less thematically and aesthetically unified phase that succeeds earlier stages of literary development. Two special issues on "Third Generation Nigerian Literature" - in English 
in Africa (2005) and Research in African Literatures (2008), both edited by Pius Adesanmi and Chris Dunton-have asserted the conceptual validity of grouping and describing texts in these terms. As its juxtaposition of signifiers implies, the label "Third Generation Nigerian Literature" welds territorial and historical registers. It groups literary works on the basis of their putative affiliation to a nation-state and their location in a historical narrative beginning with foundational figures and proceeding through stages. In their introduction to the English in Africa special issue, Adesanmi and Dunton do acknowledge that the framework has limitations-for example, in the arbitrariness of the historical cuts that separate its stages-but nonetheless argue for its heuristic value as a way of explaining the link between "temporal coevality and ideological/thematic coherence" (Adesanmi and Dunton 13). Critical debate since their field-defining intervention has offered competing accounts of the core features of "Third Generation Nigerian Literature," those specific qualities that make the corpus distinct and of its time. The theoretical implications of organizing literary critical discourse in such terms have largely been taken for granted, which is the issue explored here.

This essay engages with the discourse on "Third Generation Nigerian Literature" by interrogating its historicizing structures and exploring competing frameworks for narrating temporal change. I compare the spatio-temporal implications of the "Third Generation Nigerian Literature" concept to the forms of historical and territorial imagination constructed by two novels belonging to this corpus: Adaobi Tricia Nwaubani's I Do Not Come to You by Chance (2009) and Teju Cole's Open City (2011). By examining how these texts narrativize the links between people, place, and time, I argue that the spatio-temporal imaginaries produced by such works are more complex than the national-generational framework deployed by critics to group them. In other words, these novels (and others like them) generate models of time and space that complicate their insertion into critical narratives predicated on concepts like "generation" and "nation." My aim is neither to critique the specific insights of existing scholarship in this field, nor to provide an alternative account of what makes the "third generation" distinct. Rather, I seek to enrich the existing critical discourse on Nigerian literature by offering an alternative perspective on its dominant historicizing frameworks.

This approach is worthwhile because the questions shaping current debate on "Third Generation Nigerian Literature" have in many ways been defined by the implicit parameters of the concept itself. On the one hand, scholars have shown interest in how contemporary texts can be related to the work of earlier authors. They have asked whether the current generation should be understood as continuing with or breaking from those that came before it. On the other hand, critics have explored the politics of affiliation implicit in the third generation's narratives, asking whether these writers are committed to an ethics of (Nigerian) territorial belonging or whether they instead manifest an emergent cosmopolitan awareness predicated on transnational sympathies and global flows. Most analyses yoke these two questions together. For example, Chielozona Eze asserts that the corpus represents a literary-historical rupture insofar as its authors, motivated "by common concern for humanity irrespective of ethnic origin," are engaged in a "transcultural remapping of the monocultural idiom" of their generational predecessors (104). Others offer similar accounts, with Adesanmi and Dunton in particular defining the third generation as that born after colonialism and hence 
concerned with "nomadism, exile, displacement, and deracination," rather than the anticolonial defense of national culture that defined their forebears' projects (Adesanmi and Dunton, "Nigeria's Third Generation Writing" 16; see also Hawley; Hewett; Hron; Ouma). A narrative of disaffiliation from generational precursors is thus connected to a politics of spatial detachment. The implied break from the past leads to a cosmopolitan future in which ethico-political belonging is disconnected from the nation-state.

An alternative strand of criticism deploys the same categories to advance a less oedipal narrative. These critics argue that current Nigerian writing is more continuous than discontinuous with what came before and that it shares Achebe's engagement with a primarily local, territorially demarcated political sphere (see Achebe). For example, Madhu Krishnan argues that contemporary Nigerian civil war narratives are shaped by the experience of failed nationalism that has defined Nigeria's independent history and she suggests that such texts are marked by the unfinished business of national reconciliation. Similarly, Obi Nwakanma sees recent Igbo writing as reflective of that group's ambivalence toward the Nigerian federation-a structure of feeling that goes back to the nation's establishment amid ethno-political conflicts inherited from colonialism. A slightly different position sees the third generation as a return to origins, or a dialectical recurrence of firstgeneration commitment after second-generation disillusionment. Adélékè Adéèkó argues that the prominent contemporary themes of transnational migration and displacement are evidence of a desire to redeem the Nigerian nation by looking abroad for successful models of democratic governance to emulate. From this perspective, the continuity of the current generation with its forebears is manifest in its engagements with Nigerian history, Nigerian politics, and the ethics of being Nigerian in a world shaped by complex structures of inclusion and exclusion.

What these varying positions share is a common analytical framework and set of questions. They are primarily interested in whether the corpus named by the phrase "Third Generation Nigerian Literature" should be seen as reflecting a continuity or break with the past and whether these texts affirm a commitment to territorial community or to a cosmopolitan/transnational ideal of belonging in movement. Existing scholarship on "Third Generation Nigerian Literature" can therefore be understood as an extended exegesis of the concept itself. It asks what it means for literature to belong to a generation, and to a nation, and its analyses are shaped by the various possible combinations of these spatio-temporal configurations. Nigerian literary criticism is thereby defined by a mode of contextualization in which texts are assigned a temporal position vis-à-vis their "now" of production and address and a spatial location derived from an understanding of where they make themselves at "home" - in a national community of fellow citizens, a dislocated diaspora, or a global non-place. In this way, critical discourse ascribes meaning to texts by linking their supposed spatio-temporal positioning to forms of ethico-political affiliation-a novel can belong to a space of nationalist commitment or it can move between places in cosmopolitan fluidity.

There is, of course, heuristic value in a critical abstraction like "Third Generation Nigerian Literature," which allows texts to be grouped and subjected to historically informed analysis. However, I wish to explore some alternative strategies for conceptualizing the spatio-temporal positioning of narrative in order to suggest how existing scholarship might be supplemented, complicated, and ultimately 
enriched. Recent criticism in the emergent field of "world literature" has posed various alternative ways to conceptualize the relation between texts, histories, and communities. In this essay, I draw in particular on the example of Vilashini Cooppan, whose Worlds Within: National Narratives and Global Connections in Postcolonial Writing (2009) questions the presumed antithesis of "the national" and "the global" that, as we have seen, shapes the "Third Generation Nigerian Literature" debate. Cooppan suggests that instead of a dichotomy, these modes of spatial imagination are mutually co-constructed, so that the nation is "an entity made through movement" and persists as a specter haunting formulations of deterritorialized belonging $(2,5)$. Moreover, she suggests that linear temporalities of the kind that subtend the narrative of generational succession are oversimplifications of how time permeates literary discourse. Drawing on the work of Fredric Jameson and Ian Baucom, she argues that genres such as the novel function rather as sites of temporal "accumulation," in which "the past finds itself not simply succeeded by the present but incorporated into it" (Cooppan 6; see Jameson 140-41; Baucom 18-31). This notion of the spatio-temporal imaginary of the postcolonial novel as multiple, accumulative, and ambivalent complicates the attempt to locate literary texts within crisply demarcated historical and territorial frames. ${ }^{1}$ As Cooppan puts it, each text is a site of "connection that regularly intercalates one time and one space with others" (4)-revealing the persistence of territorial community in a globally minded ethos like cosmopolitanism and showing the recurrence of the past in presents haunted by times and spaces that exceed them. I argue that approaching "Third Generation Nigerian Literature" from this perspective will enable us to explore how fictional narratives are shaped by ambivalent spatio-temporal constructs that encompass and exceed the generational-national framework.

There are many novels that could inform this analysis. Recent works by, for example, Chris Abani, Chimamanda Ngozi Adichie, and Helon Habila explore the possibilities of transnational settings and the interpenetration of the global and the national. I have chosen Nwaubani's and Cole's novels not because I wish to suggest that they are representative of this broader corpus, nor that their spatio-temporal ambivalence is unique or somehow more extreme than that of other texts. Rather, these two novels-which have not yet been subject to extended critical analysis - simply provide a valuable illustration of the phenomena I wish to examine, allowing the tensions between contemporary Nigerian fiction and the "Third Generation Nigerian Literature" concept to appear in a clear light. Both novels explore the problem of spatio-temporal location, as their characters struggle to place themselves in social environments overlaid with alternative ideals of political affiliation, each supported by competing accounts of historical change. I Do Not Come to You by Chance concerns the experiences of Kingsley Ibe, an educated Igbo man trying to establish himself in a contemporary Nigeria that, despite its return to democracy, continues to be plagued by corruption and a lack of opportunities. Kingsley must choose between following his father, for whom advancement comes from education and legitimate employment, and his uncle, a businessman engaged in " 419 " - the fraud industry named after the relevant section of the Nigerian penal code, most well known internationally for the sending of unsolicited emails inviting recipients to invest in fake philanthropic causes or business opportunities. Focusing on the phenomenon of Internet fraud allows Nwaubani to position her Nigerian setting, with its class divisions, within 
a transnational context in which new technologies offer a path, albeit illegal, around the barriers that till now have kept most Africans at the bottom of the global politico-economic hierarchy.

Open City, by contrast, approaches the global-local nexus from the perspective of migration. Its Nigerian-born protagonist, Julius, is a self-consciously cosmopolitan New Yorker, whose long walks across the city prompt reflections on the patterns of immigration and exile that constitute the layered historicism of the urban space. Unlike Kingsley, whose forays into transnational crime are prompted by obligations to family and community, Julius resists all attempts to fix him to a stable spatio-temporal location. He denies the need for rootedness in favor of a mannered performance of worldly sophistication-a pretense masking repressed memories that, when revealed, undermine his celebration of cosmopolitan disinterestedness. I argue that juxtaposing the construction of time and territory in these two novels reveals how spatio-historical frameworks can vary widely from text to text, constituting both an important theme and implicit ideological dimension of their narratives. The "Third Generation Nigerian Literature" concept itself constructs an analogous framework of temporality and territoriality. Bringing the historicizing procedures of literary criticism into contact with those of the literary texts it purports to describe can, I suggest, open new avenues for thinking through the relations between time, space, and narrative in literature.

I Do Not Come to You by Chance explores how individuals locate themselves within concentric circles of imaginative affiliation. Familial, regional, national, and transnational layers of belonging envelop Nwaubani's characters, imposing variable, potentially competing demands on them. Her comic narrative traces how the contradictions between these spaces can be addressed by reference to shared understandings of past injustice, present necessity, or future possibility. As such, a major focus of the novel concerns the historical narratives produced by those engaged in Internet fraud. These implicit parables or apologia seek to justify 419 by explaining why it is acceptable for certain people here to defraud others there. In so doing, they presume a relationship between territory and temporality, explaining ethical obligations as the product of a subject's specific location in space and time. Simultaneously, these accounts are undermined by Nwaubani's irony. The novel's narratorial address invites readers to approach characters as members of a shared imaginative world, thereby deconstructing the patterns of inclusion and exclusion they were striving to establish. I Do Not Come to You by Chance is mobilized by the tension between these competing frameworks for locating individuals in space and time, making it, I argue, a dramatization of the potential ambivalence of the spatio-temporal imaginary.

Nwaubani's protagonist, Kingsley, is a young Nigerian graduate whose degree in chemical engineering is insufficient for securing a job. When his father dies unexpectedly, Kingsley is left with the responsibility of providing for his family and must choose whether to persist in honest struggle or accept his uncle's invitation into 419. The latter offers the consumer lifestyle that, for Kingsley (and the women he desires), is a dream worth almost any sacrifice-especially when its foreign victims are depersonalized and naïve. Nwaubani contextualizes this 
narrative within a national setting defined above all by class inequality, rather than the regional, ethno-linguistic, or religious divisions that frequently mobilize Nigerian fiction. Corruption has hollowed out the state and left citizens to fend for themselves in an environment in which "long leg" — social connection-is more important than qualification or capability (Nwaubani 28). In such a context, the question of how to live ethically has immediate consequences not only for Kingsley, but also for his family and friends. The risk of social decline is real and the misery of those at the bottom of the class hierarchy is enough to make even the most idealistic question how much they will pay for their principles.

Kingsley's options for how to respond to this dilemma are personified in the form of alternative parental figures-father Paulinus and uncle Boniface. To this extent, I Do Not Come to You by Chance is indeed a generational narrative of the kind described above. The alternatives offered by Kingsley's male relatives do represent, respectively, continuity or discontinuity with the ideals of the independence period and Kingsley is implicitly engaging with some of the questions that have motivated the criticism of "Third Generation Nigerian Literature" - whether he should align himself with a territorially demarcated community and try to redeem the promises of nationalism or seize the opportunities of new technology to forge a different relation with the world. Nwaubani's novel examines what it means to be a young Nigerian in a contemporary society in which old ideas are being rethought. However, far from an unequivocal endorsement of the approach encoded in the "Third Generation Nigerian Literature" concept, I argue that close analysis of the terms in which each of Kingsley's alternatives are framed demonstrates the extent to which Nwaubani's spatio-temporal constructs are more complex and multidimensional than those of most existing criticism.

Paulinus's ideals are associated with the preindependence period by the novel's prologue, which depicts him at the height of his social prestige, newly returned from university in the United Kingdom and wooing Kingsley's future mother (3-10). For Paulinus, the new nation represents a genuine hope for social transformation. "The past is constraining but the future has no limits," he declares (7). He fervently believes education is the means to achieve this liberation, telling Kingsley that "without education, man is as though in a closed room; with education, he finds himself in a room with all its windows open towards the outside world" (16). Yet this association of education with "the outside world" points to the paradox in Paulinus's progressive nationalism. He assumes that time moves in a linear direction from "constraining" past to limitless future, but also ascribes implicit territorial signifiers to these temporal concepts. In his description, the past is associated with here - the proximity of village, region, Nigeria, or Africaand the future with there-Europe or America. For example, he claims that "the more temperate weather conditions" of countries inhabited by white people "made it easier to think creatively" (145), explaining technological advancement as the result of superior foreign geography. He also vaunts the alleged capacity of Western clothing to facilitate original thought, prompting others to mock him as "the white man whose father is black" (145). The novel thus presents Paulinus as embodying the contradictions of modernizing nationalism. He affirms that through education young Nigerians can improve their own lives and help their country develop, but by equating "development" with geographical and cultural distance-the extent to which one emulates the difference of the West-he makes 
it conceptually impossible for Nigeria to escape its supposed backwardness. For the country to progress would mean liberation from itself. ${ }^{2}$

When the novel shifts from this preindependence prologue to its primary setting in the post-Abacha period, these ideals are repositioned as those of a time now passed. Paulinus falls ill and dies and Kingsley has no choice but to turn for financial assistance to a very different paternal figure. Uncle Boniface, or "Cash Daddy," lacks Paulinus's formal education, but has made himself wealthy through illegal business ventures. He is a grotesque comic character, depriving rich Westerners of their money through elaborate schemes and ruling an empire of sycophantic dependents-whom he directs from meetings held, among other places, on his toilet (111-12). He dispenses his wealth with limitless generosity, refusing to converse with Kingsley until his tattered shoes have been replaced (95-96) and paying Paulinus's medical and funeral expenses without hesitation (102). Like Kingsley's father, Cash Daddy's sense of obligation to his family is absolute: "When the eye weeps, the nose also weeps," he tells his nephew, reminding him of the debts owed to those socially and physically proximate (124). The proceeds of crime allow Cash Daddy to have what Paulinus wanted but could never afford: security for himself and his dependents, access to imported clothing and food, and the freedom to travel. As circumstances compel Kingsley to renounce his loyalty to his father's ideals and accept Cash Daddy's help, Nwaubani implies that it is the latter who personifies the social and economic forces shaping contemporary Nigeria. If Paulinus embodies the dreams of independence, Cash Daddy is his generational successor, the representative hero of the new dispensation.

Once ensconced in the world of 419 and actively engaged in defrauding foreigners, Kingsley and his coworkers find it necessary to rationalize their actions. There are at least four major justifications for 419 offered by characters in I Do Not Come to You by Chance, each of which constitutes a theorization of the relationship between fraudster and victim and the nature of the obligations this entails. These rationalizations link modes of spatio-temporal positioning-as characters explain what it means to belong to a particular place at a specific moment in time-to an understanding of ethical behavior: what does a person here owe to someone there at this point in history? I argue that these rationalizations form the conceptual heart of the novel, as Nwaubani meditates on the complexity of the spatio-temporal imaginary underpinning her characters' views of the world.

The first rationalization holds that ethical obligations diminish as physical and social distance increases, reaching a terminal point at the nation's boundary. Thus "stealing from your own brothers and sisters"-like the corrupt politicians who rob their constituents-is "the abyss of wickedness, especially when you had the firsthand opportunity to witness their daily suffering and struggles" (210). Defrauding Europeans and Americans, by contrast, is no crime at all, for no one could be expected to take responsibility for the well-being of "a bunch of email addresses with no real people at the other end" (151). When Kingsley makes the mistake of imagining the effect of his actions on one of his victims, Cash Daddy explains exactly where and to whom his obligations rest: "'Is she your sister?' . . 'No.' 'Is she your cousin?' 'No.' 'Is she your brother's wife?' 'No.' 'Is she your mother's sister?' . . . 'No.' 'Is she your father's sister?' ‘No.' . . 'Is she from your village?' ‘No.' 'So why are you swallowing Panadol for another person's headache?'” (157-58). The extended family functions here as the novel's metaphor of social placement, 
locating the subject within an environment divided between those who are like-minded and culturally similar - to whom obligations are owed-and those rendered unfamiliar by their material circumstances. Cultural and geographical distance thus negates ethical responsibility, for as Cash Daddy explains, "oyibo people are different from us.... They don't know anything about suffering" (158).

Significantly, the novel is ambiguous as to whether this boundary between inside and outside coincides exactly with the nation-state's borders or whether there are significant internal divisions that undermine it. As with most anglophone Nigerian fiction, the Northern region is absent from the narrative and the question of whether Cash Daddy's familial metaphor includes, say, Muslim Nigerians, is left unresolved. Moreover, the process of actually inscribing this boundary between inside and outside exhibits a phenomenon of spatial ambivalence identified by Cooppan, in which the subject achieves symbolic affiliation with a bounded space through his or her encounter with the global. As she puts it, "national territory ... has never been purely itself, purely national, but instead [is] always constituted, in both its imperial and anti-imperial modes, through a co-constitutive relationship with some internal and external other" (18). This process of constructing spatial boundaries through their traversal can be seen in a passage exemplary of 419's first rationalization. One of Kingsley's colleagues adopts the persona of a young white woman and befriends an American man online, whom "she" convinces to part with his money by telling him her wallet has been stolen while vacationing in Nigeria. Kingsley is impressed by the 419er's capacity to mimic the speech patterns of a society he has observed only through its commodified images and by the fact that a real American cannot recognize the simulation (162). The 419er's illusion comes under strain, however, when his victim expresses derogatory attitudes toward Nigerians, declaring that "almost all of them over there" have "diseases, especially HIV" (164).

\footnotetext{
All of us standing around the screen stopped giggling. In the ensuing silence, I could almost hear the whisperings of our national pledge. I pledge to Nigeria my country/To be faithful, loyal, and honest....

The faint voice of patriotism must have ministered to the young Nigerian.

"It's not like that in Nigeria," he replied. "It's in South Africa that they've got it so bad."

"Is it? Anyway, you've still got to be careful. All them places are all the same thing to me." (164)
}

In this passage, Kingsley's affective identification with his nation is mediated by the American's racist stereotyping of Nigerians. The fraudsters experience this slight as a prompt to assert their identity as distinct not only from the wealthy outsider, but also from other African nationalities-before the homogenizing gaze of the foreigner, specificity becomes a source of pride. The episode ends with Kingsley, comfortable he owes nothing to people so ignorant of his society, sending another fraudulent email to ensnare new victims. The novel thus depicts the global encounter with a culturally and physically distant outsider as the ground on which national self-identification is established. The assumption that ethical obligations cannot cross national boundaries is itself reinforced by the experience of imaginative border-crossing, of viewing oneself in the gaze of another. 
The second major rationalization of 419 adds a historical dimension to this spatial distribution of ethical obligations. The young fraudsters justify their actions by constructing a narrative of previous encounters between Nigeria and the outside world, one that explains why they should care only for their figurative families. Kingsley's qualms about his actions are once again the prompt for Cash Daddy to introduce this justification: "You, you went to school," he expostulates. "Did they not teach you about the slave trade? . . Who were the people behind it? And all the things they stole from Africa, have they paid us back?" (158). Slavery and colonialism are invoked as prior moments in an ongoing encounter between us and them, with each collective subject understood to possess an identity stable across time. From this perspective, world history is a process of constant oscillation in which certain regions exploit the power of new technology to enrich themselves at the expense of others, until they are eventually displaced when their victims master the technology in turn. The 419ers are thus simply doing to Westerners what Westerners did to them when they could and would do again if they had the chance. Kingsley concludes that, given this anarchic dynamic, present-day Nigerian fraudsters should view their actions not as a crime, but as a rebalancing of their country's hitherto unequal relationship to the outside world: "What was there to be guilty about? Was anybody feeling guilty about the artefacts and natural resources pilfered from Africa over the centuries?" (258).

While this explanation defuses criticism of 419 by asserting the amorality of international relations, it also implicitly legitimizes imperialism by suggesting that any society, once strong enough, will strive to dominate others. As such, the third rationalization of Internet fraud appears in the reemergence of racist and imperialist terminology, which is appropriated by the 419ers to dehumanize their victims - or "mugus," a common Nigerian pidgin term used in the novel to describe those "stupid enough to fall prey to an email from a stranger in Nigeria" (151). ${ }^{3}$ When one of Kingsley's colleagues tries to defraud the wrong kind of foreigner and is caught, Cash Daddy reminds Kingsley of the pseudo-Darwinian, hierarchical nature of race, in which peoples accustomed to being exploited acquire an adaptive advantage over those made weak by comfort:

There are mugus in America, Britain, Germany, Russia, Argentina, France, Brazil, Switzerland, Spain, Australia, Canada, Japan, Belgium, New Zealand, Italy, Netherlands, Denmark, Norway. . . . Even Israel. There are mugus all over the world. Yet it's the one in Iran that Azuka went to look for. Doesn't he know that those ones are not real oyibo people? Their level of mugu is not as high. In fact, they are almost as smart as we are. (312-13)

This attitude holds that the 419ers' knowledge of the world makes them superior to their prey, whose foolishness deserves to be punished. When Cash Daddy succeeds in a brilliant plot to extort money from an Argentinian investor by posing as the Nigerian Minister of Aviation, Kingsley revels in the reversal that sees a white man-supposedly "several scales ahead of me in the evolutionary process"behaving "like a seasoned ignoramus" (201). From a world in which Europeans treated Africans as subhuman, Kingsley can now scoff at their bestial stupidity and enjoy the knowledge that his sophistication and wile make him a natural master: "I could not vouch for the entire black race, but the niggers of Nigeria were 
certainly not monkeys" (218). To this extent, the novel celebrates the overturning of social hierarchies and the capacity of terms of abuse to be resignified as new structures of power emerge. ${ }^{4}$

However, the return of this language of racial inequality marks the 419ers' world as one without progress. Their understanding of history as a process of oscillation between centers of dominance and peripheries of exploitation cannot lead to the development of a more just society, but only to ceaseless, nondirectional change, as the exploited break their chains and enslave their masters in turn. As such, this nonprogressive historical narrative undercuts the generational structure established in the novel by Kingsley's choice of paternal models. Where the generational narrative implies a history of meaningful change in which new ways of being supplant the old, the historical vision of 419 sees but an endless struggle for survival, a battle to rule or be ruled. These two models of affiliation-the generational dilemma of affirming or denying Paulinus's ideals of independence and the 419ers' binary distinction between familial "inside" and foreign "outside" - thus produce dissimilar temporal formations that coexist in the narrative.

The fourth and final rationalization of Internet fraud complicates this spatiotemporal construct further. It reintroduces the possibility of national development-and thus progressive temporality-as the paradoxical outcome of global economic struggle. This justification holds that Internet fraud can solve the problems of class inequality and corruption discussed above, as the money extracted from mugus trickles down to produce material improvements for the local community. Kingsley notes how this works in enumerating how the 419ers fulfill their obligations to those who live in their proximate environment:

Cash Daddy was personally responsible for the upkeep of the 221 orphans in the Daughters of St Jacinta Orphanage, Aba. He tarred all the roads in my mother's local community. He dug boreholes, installed streetlights, built a primary healthcare centre. Just two days ago, I received a letter from the Old Boys' Association of my secondary school requesting my contribution towards a new classroom block. I replied immediately to say I would fund the whole project. (226)

Kingsley depicts 419 as the source of funds for education, roads, medical, and social services-fulfilling the developmental role left absent by the corrupt state. This is both the reversal and ironic fulfillment of the model of socially engaged nationalism embodied by Paulinus. Where his ideals depended on Nigeria adopting a Western template of progress, Cash Daddy's pirate capitalism achieves superior results by exploiting the foreigners who no longer represent civilization or advancement. Cash Daddy's world is thus one in which two distinct temporal zones coexist-the anarchic, nonprogressive space of global economic conflict and a bounded territory of affiliation that can be progressively improved by investing the profits extracted from the former sphere. Kingsley notes the differential ethical structure these spaces entail when he observes that, in such a world, concern for the well-being of mugus is irresponsible: "Not being able to take care of my family was the real sin" (159).

In this way, I Do Not Come to You by Chance depicts complex frameworks for linking modes of spatial and temporal placement to ethical norms. Nwaubani's 
characters construct multilayered systems for explaining the difference between here and there and elucidating the differential modes of behavior required in each space. At the level of diegesis, these systems are oriented toward establishing boundaries between local communities of affiliation and an amoral external world. However, there is an additional layer of complexity to Nwaubani's spatio-temporal imaginary. When we turn from the represented world to the level of form, a new pattern emerges, one that deconstructs her characters' attempts to narrate the differences between inside and outside and instead traverses boundaries through the cross-border appeal of sympathetic imagination.

I Do Not Come to You by Chance is an example of what Eileen Julien calls an "extroverted" African novel, "a particular type of narrative characterized above all by its intertextuality with hegemonic or global discourses and its appeal across borders" (681). Nwaubani's narrative represents the closed world of Nigerian Internet fraud through tropes derived from transnational literary exchange and-to some extent-with a non-Nigerian readership also in mind. Julien observes that the effect of the "extroversion" of texts that "speak outward and represent locality to nonlocal others" is to produce a kind of narrative "which physically crosses borders and thematizes border crossings" (684, 689-90). This effect is apparent in Nwaubani's inclusion of examples of genuine 419 emails. These profoundly funny texts invite their recipients to profit from the hidden millions of Sani Abacha (15254), access corrupt government contracts (265), rescue Nigerian astronauts trapped in space (103), and even assist Christian converts escape the 419 lifestyle (206-07). The emails partly validate the 419ers' belief in their own adaptive superiority by demonstrating how such crime relies on an epistemological asymmetry between fraudster and victim-success is possible only because the Nigerian perpetrators know more about Western culture and beliefs than vice versa. However, the inclusion of these texts also produces irony, as readers are invited to witness such exchanges with a level of knowledge exceeding both sides. The joke only works, that is, if readers are placed in an epistemological situation from which the 419ers' deceit can be recognized.

The novel thus presumes its readers' capacity to, in Shameem Black's description, apply sympathetic insight to imagining "the lives of others" (61). The epistemological asymmetry between (Nigerian) inside and (global) outside is deconstructed by this ironic form. The implied reader-wherever in the world he or she lives-encounters Nwaubani's characters as inhabitants of a shared imaginative space defined by epistemological permeability, a framework within which Kingsley's belief in his evolutionary superiority is proved false by our capacity to understand his life, recognize his dishonesty, and sympathize with the circumstances that have led him to crime. Black defines this imaginative relationship as one of proximity, as narrative creates an encounter in which "the borders of the self jostle against the edges of others, and ... the contours of each ... become more porous and flexible" (47). Nwaubani's characters' attempts to erect fixed boundaries between interior and exterior space - the former to which one owes ethical obligations and the latter, which is the site of amoral self-enrichment-are undone by this formal logic of sympathetic identification and cross-border understanding.

I Do Not Come to You by Chance is therefore characterized by a tension between its characters' attempts to establish a local space of obligation isolated from the outside world of non-progressive struggle and the pattern of sympathetic, 
cross-border imagination implied by its ironic, extroverted form. Spatio-temporal structures defined by territoriality coexist in dynamic interrelation with those defined by the imaginative transcendence of place. Linear, repetitive, and nondirectional temporalities are further cross-hatched by a framework of simultaneity akin to what Benedict Anderson describes as the "sociological landscape" constructed by the novel-reader's omniscient gaze (35). Nwaubani's text is the site of multiple, overlapping, and frequently contradictory ways of narrating relationships between space, time, and subjects. Some-but only some-of these depend on the concept of the generation to reflect on how contemporary Nigerians might negotiate the legacies of independence and the challenges of globalization. The structures of spatio-temporal placement that dominate "Third Generation Nigerian Literature" criticism are therefore supplemented in Nwaubani's text by patterns more reminiscent of Cooppan's analysis. The result is a novel defined by the mutual entanglement of times and places, in which the territorial is overwritten by the global and the present is haunted by temporalities that exceed it.

To demonstrate how this interweaving of ambivalent spatio-temporal forms permeates different texts in specific ways, I will turn now to a very different novel-one self-consciously located far from Nwaubani's Nigeria and that explores the possibility of transcending the patterns of ethical affiliation that define Kingsley's world. Teju Cole's work represents an additional elaboration of the spatio-temporal imaginary, placing further strain on the frameworks currently proposed for imagining time and territory in "Third Generation Nigerian Literature."

Julius, the protagonist of Open City, strongly resists the pressures of collective identification, objecting to the belief that accidents of birth, race, or family should entail ethical obligations. He refuses to engage in the negotiations of local, national, and transnational affiliations that shape Kingsley's social self-positioning. He is instead ambivalently located between identity markers, not so much seeking to integrate various ties than exploiting their nonalignment to open a space for individual freedom. The son of a deceased (and idolized) Nigerian father and an estranged German mother, Julius works as a psychiatrist in New York City-the global metropolis par excellence. He admits his Nigerian nationality only when pressed and then with an ironic disavowal of its claim to encompass identity. Cole's and Nwaubani's novels thereby construct contrasting models of territoriality and temporality. If the latter seeks to map the overlapping networks of affiliation that locate individuals in historical time and social space, Open City explores the spatio-temporal coordinates of a selfhood not in place in the world. It interrogates the cultural politics of such non-belonging.

Cole's narrative is shaped by Julius's attempts to project a self-consciously cosmopolitan persona unbounded by a proximate locale. His thoughts and memories, which constitute the first-person narrative, display a worldly erudition that spans European, American, Asian, and African history, art, and culture-from Mahler to Fela Kuti, Walter Benjamin to the slave trade, Freud to the Haitian Revolution. He cites paintings by El Greco and Courbet in describing the death of his father (228) and refers approvingly to Kwame Anthony Appiah's account 
of cosmopolitanism as an ideal of global belonging (186). Rather than locating its characters in a singular spatio-temporal location comprised of overlapping frames, such juxtapositions allow Open City to explore spaces defined by the dissolution of territorial boundaries and the mutability of historical time-places shaped by the interpenetration of disparate scenes in the consciousness of its protagonist. This fluidity is exemplified by Cole's key motif: the long walks Julius takes through the streets of New York and Brussels, which prompt his stream-of-consciousness traversals of time and space and in which he strives to emulate birds and their "miracle of natural immigration" (4).

By walking through the city, Julius maps time onto space, so that history emerges less as an unfolding sequence of events than as material traces inscribed on the physical environment. This is especially true of New York, which he understands as the product of innumerable migrations and cross-cultural encounters, each of which has left a mark-either visible or in the form of an absence meaningful to those who can read it. For example, Julius views the void at the World Trade Center site as a reminder not only of the terrorist attack, but also of layers of history behind the events of 2001:

This was not the first erasure on the site. Before the towers had gone up, there had been a bustling network of little streets traversing this part of town. . . . Gone, too, was the old Washington Market, the active piers, the fishwives, the Christian Syrian enclave that was established here in the late 1800s. . . And, before that? What Lenape paths lay buried beneath the rubble? The site was a palimpsest, as was all the city, written, erased, rewritten. (58-59)

Experiencing the city as a palimpsest means that for Julius the present is suffused with an awareness of past generations. History is lost but persists, locating the narrative moment within an unfolding process of creation and destruction in which individual lives shrink to relative insignificance. From this perspective, Julius is but "one of the still legible crowd," part of the tide of humanity "rush[ing] through the eye of the needle" (59). His moment of existence is no more significant-no more real- than any that was or is yet to be.

The temporality produced by this awareness lacks both origin and telos. Necessarily nonlinear, it contrasts with the progressive histories found at certain points of I Do Not Come to You by Chance, but differs also from that novel's anarchic or non-directional historicisms. In Open City, moments of greater or lesser chronological and geographical proximity are juxtaposed when visual or memorial cues bring them to Julius's attention. On one of his walks, for instance, Julius meets a Haitian bootblack who recounts a life story of slavery, revolution, and dispossession-a tale that belongs more properly to the eighteenth and nineteenth centuries than to Julius's 2010 (70-74). Viewing the city after this encounter, Julius feels chronologically unsettled, as though anachronism has intruded into the present:

That afternoon, during which I flitted in and out of myself, when time became elastic and voices cut out of the past into the present, the heart of the city was gripped by what seemed to be a commotion from an earlier time. I feared being caught up in what, it seemed to me, were draft riots.... What I saw next gave me a fright: in the farther distance, beyond the listless crowd, the body of a lynched man dangling from a tree. (74-75) 
This uncanny experience recalls Cooppan's description of accumulative temporality, in which "the past finds itself not simply succeeded by the present but incorporated into it" (6). Elsewhere Julius alludes to Walter Benjamin's "Theses on the Philosophy of History," in which a form of temporal consciousness akin to this is described as a "constellation" between the present and an image of the past that "flashes up at a moment of danger" (Benjamin 257). Perceiving historical time as a constellation of causally unconnected moments disrupts the stability of the present, throwing into doubt the assumption that entities presumed lost-like the successive erasures beneath the rubble of Ground Zero-have, indeed, been destroyed. As Julius observes of "the generations of New Yorkers" who preceded him, each "one of those past moments was present now as a trace" (54). These remnants endure as a reminder that other times and ways of living can exist as possible alternatives to the homogeneous now.

These traces are however visible only to the informed observer, a privileged individual with the knowledge to recognize significant conjunctions of past and present. The novel's spatio-temporal imaginary thus places enormous weight on its protagonist's erudition to mediate its historical leaps. At times this strains Julius's plausibility as a character, as he holds forth with detailed historical knowledge tonally reminiscent of an encyclopedia or guidebook rather than the interior monologue it purports to be. During one walk across Manhattan, for instance, Julius reflects on the design of certain structures. He explains, with a specificity that strains credibility, how they reflect shifting patterns of wealth and fashion over time:

Across the street from El Malecon was a massive and architecturally bizarre building. It had been built in 1930, and was known back then as the Loews 175th Street Theatre. Designed by Thomas W. Lamb, it was filled with glamorous detail—chandeliers, red carpeting, a profusion of architectural ornament within and without... The theatre, America's third largest when it was built, seating over three thousand, had hosted films as well as vaudeville shows in its earlier incarnation. Al Jonson had played there, as had Lucille Ball, and back then it had been surrounded by expensive restaurants and luxury goods shops. (234-35)

This scene is framed as a depiction of Julius's inner life, but the level of factual detail suggests someone quoting from written sources rather than daydreaming on a stroll across town. In such passages, which recur on themes ranging from popular culture to ornithology, Open City seems less like a representation of its protagonist's consciousness than a vehicle for extraneous historical knowledge. These moments reveal how Cole's novel is shaped by an apparent tension between its "historical" and "psychological" dimensions-its focus on an individual mind in a single place and time, on the one hand, and the collective life of the city over centuries, on the other. It is as though the novel's examination of New York's past presses against its limited focalization in Julius's psychology, creating a disjuncture reflected as tonal implausibility.

This criticism has been leveled at Open City, with some readers declaring Julius to be an improbable creation, a pretentious know-it-all whose impossible cleverness is alienating. Reviewer Jim Hannan, for example, describes the novel as "a grab bag of eclectic references" that parades its cosmopolitan "learnedness 
... like a clumsy book report" (59). He observes that for Julius, "obscure historical facts" function not only to invoke the city's past, but also as a protective barrierone that repels readers and characters alike. Hannan describes this as Julius's "detachment" from "the lives being lived all around" him (60) and the term is apt, for when confronted by situations in which he is invited to share intimacy, Julius always disengages, assessing his interlocutors with clinical distance rather than sympathetic engagement. Frequent attempts by other black men to connect on the grounds of race are met with pained withdrawal, for example, and an unexpected sexual encounter with a Czech tourist-whose name he instantly forgets-is for Julius nothing more than "desire fulfilled without complication" $(110,146)$. He goes so far as to declare social commitments to be dangerous, a "lure of violence" or potential means to rationalize brutality, that ought to be avoided "by having no causes, by being magnificently isolated from all loyalties" (107). Julius's emotional disinterestedness is as carefully cultivated as his erudition. His alienating qualities are not, therefore, accidental, but are fundamental to Open City's examination of how individuals locate themselves in history and territory-in other words, to the novel's analysis of spatio-temporal imaginaries.

The association Cole draws between his protagonist's detachment and his mannered knowingness is not incidental because it is precisely Julius's social isolation that allows him to construct links between what he witnesses and other times and places. For example, in Brussels he converses with a young Moroccan immigrant about the plight of Palestinian refugees and the hostility directed against Muslims in Europe. While intrigued by the man's ideas, Julius remains intellectually aloof, noting his "slightly inaccurate quotation of [Golda] Meir" and comparing his account of contemporary racism to Brussels's reputation for cosmopolitanism in the early modern period (105-06). Julius's obsessive display of erudition-he ends one discussion of Belgian race relations with an allusion to fifteenth-century painting (106) and another with a pastiche of James Joyce's The Dead (146) - is enabled by such intellectual and affective distance. The perspective that allows him to see himself as "one of the still legible crowd" in a present that is not unique is the product of this resistance to attachments, his commitment to remaining "magnificently isolated" from those around him. The novel's vision of urban societies comprised of the sedimented traces of past convergences emerges from the consciousness of a subject unbound by the ties that connect others to specific spatio-temporal sites of affiliation. Open City thereby suggests that its account of a disinterested cosmopolitan ethos is an attitude belonging to the subject who belongs to nowhere.

This view from nowhere is not, however, a neutral one. Julius's walks take him through cities that form the economic and political core of the United States and European Union. His carefully performed cosmopolitanism is staged in the global metropole, rather than its periphery, and its precondition is his (classspecific) capacity to travel and study. This privileged position recalls Anthony Pagden's critique of cosmopolitanism. Pagden argues that the equation of "world" and "home" that defines the cosmopolitan ethos is not, as it may seem, a necessarily progressive appeal to relativism and cross-cultural respect. Rather, the cosmopolitan ideal has traditionally emerged in moments of imperial expansion when the world becomes the object of desire for an elite that considers itself to possess its logos and hence the right to define who does and does not belong (Pagden). 
From this perspective, Julius's aloofness can be read as an implicit challenge to the celebration of cosmopolitanism found in much "Third Generation Nigerian Literature" discourse. In particular, Eze's argument that the current generation marks the emergence of a "cosmopolitan solidarity" practiced by those who have "transcended . . . bigoted interest" (103) fails to account for Julius-for whom the transcendence of proximity leads not to solidarity across distance, but to the aristocratic individualism of the wealthy New Yorker. His refusal to participate in the negotiations of belonging, that for Kingsley define social existence, is the price of this metropolitan citizenship, the condition of Julius's capacity to view all places and times as equal. Open City thereby demonstrates that Julius's notion of history as a decentered constellation is not, in itself, a placeless concept: it is specific to his location at the heart of global politico-economic power. The novel's spatiotemporal imaginary is thus, paradoxically, rooted in a particular time and place, without which its pretense of unboundedness would be incoherent.

Julius's grounding in his metropolitan context is not the only way in which his claim to have achieved the "magnificent isolation" of non-attachment is undermined. The narrative is scattered with clues that further complicate his imaginative self-positioning, suggesting how his spatio-temporal consciousness is dependent on a territorially defined imaginative substrate in ways of which he is unaware. An early scene detailing his meeting with a former English professor hints at the existence of hidden elements to his narrative. He observes that from this teacher he learned "the art of listening ... and the ability to trace out a story from what was omitted" (9)-skills, we infer, that ought to be applied to Open City itself. Elsewhere Julius discusses his occupation as a psychiatrist, observing that its practice entails a form of hermeneutics in which mental realities must be deduced from often-deceptive external manifestations. A degree of suspicion toward others' self-understanding is essential, for "the mind is able to deceive itself," being the "lens through which the symptoms [of mental illness] are viewed [that] is often, itself, symptomatic" (238). These observations suggest that we ought to apply a reading method to Julius's narrative analogous to his approach to the traces of history-recognizing the presence of a story not only in what is visible, but also in what has been erased. I argue that such a method reveals a repressed structure of spatio-temporal fixity lying beneath Julius's mannered cosmopolitanism, one that functions as its implicit precondition.

We can see this by examining the narrative significance of the object that is most insistently absent to Julius - his country of birth and schooling. He describes Nigeria as "mostly forgotten," a past that is "empty space, great expanses of nothing, in which [a few] significant persons and events float" (155). This description prefaces his first meeting with Moji Kasali, "a friend, or rather an acquaintance whom memory now made convenient to think of as a friend," whom he had, like Nigeria, "long forgotten" (156). The narrative juxtaposition of Moji and Nigeria establishes a metonymic association between them, so that Julius's encounters with her mediate his imagined relationship with his homeland. Moji is committed to her various social locations - and to negotiating their contradictions - to a degree reminiscent of Kingsley. Otherwise terrified of climate change, for instance, she flies regularly to Nigeria, maintaining familial relationships at the expense of the environment (198). She is also far more personally affronted by racism than Julius. She identifies it as the underlying cause of social problems in the United 
States, drawing a causal-and hence narrative rather than constellational—connection between present inequity and past violence (203). Julius finds Moji intriguing and desirable and, after meeting her, his narrative turns, without explicit prompting, to thoughts of his parents-especially his father's death in Nigeria, implicitly contrasted to his mother's birth in Berlin at the time of mass rape during the Red Army's occupation (223-27, 78-81). Moji's arrival thus prompts a narrative shift in which abstract reflections on history and migration become interspersed with a more personal exploration of Julius's transnational selfhood.

This trajectory culminates in the revelation of Julius's unreliability as a narrator and of the extent to which he has repressed unpalatable truths about himself. At a party to which she invites him, Moji recounts an event Julius claims to have utterly forgotten: as a teenager in Nigeria, when she was drunk and unable to resist, he had raped her. He offers no reply to her accusation, instead turning, as always, to historical comparisons-an anecdote about Nietzsche (246). He silently acknowledges the convincingness of her story, however, and is unsettled by the extent to which this disremembered event undermines his self-understanding:

Each person must, on some level, take himself as the calibrating point for normalcy, must assume that the room of his own mind is not, cannot be, entirely opaque to him. Perhaps this is what we mean by sanity: that ... we are not the villains of our own stories. ... And so, what does it mean when, in someone else's version, I am the villain? (243)

Moji's accusation targets not only Julius's criminal actions. She castigates him above all for forgetting her, for implying that the present can escape its constitutive relation with the past and individuals disentangle lives that have once been knitted together. "Things don't go away just because you choose to forget them" (245). Moji thus reveals not only Julius's hidden capacity for brutality, but also the ethical flaw of his attitude toward the unconnectedness of place and person. Julius's purported capacity to view the world impartially from the perspective of one owing nothing to particular spatio-temporal locations is revealed to be self-interested, the (unconscious) strategy of one guilty about the negative impact his life has had on another. Julius's attempt to dissociate himself from his context and drift in an imagined world without boundaries is revealed to be unviable, for he has always been embedded in a social environment in which his actions affect those around him. "I had been ever present in her life," he admits, "like a stain or a scar, and she had thought of me, either fleetingly or in extended agonies, for almost every day of her adult life" (244).

A form of spatio-temporal fixity thus reappears at the end of Open City as the hidden precondition of Julius's cosmopolitan ethos. His fantasy of a mode of existence in which spatio-temporal locations can be constellated to create an ungrounded, non-teleological historical awareness functions to repress the memory of a specific action that happened in a particular time and place and that, for its victim, is never comparable to anything else. That the event took place in Nigeria and involved a character metonymically associated with that nation is consistent with its function as a critique of Julius's mannered cosmopolitanism. As Cooppan argues in her analysis of the discourse of globalism, such returns of the national reflect its function as the repressed ground on which fantasies of 
unbounded movement occur. The nation is a specter that always returns, haunting the global with images of bounded space and historical times of origins and becoming, unsettling the desire to imagine a world only of flow (Cooppan). Moji's undoing of Julius's pretentions thus marks the return of what he abandoned in becoming a citizen of (metropolitan) nowhere: the attachments that define the subject as unavoidably affiliated with particular places (however defined) in specific times (however narrated). This conclusion is exemplified by the image with which the novel ends - of the thousands of birds killed by colliding with the Statue of Liberty, the "miracle of natural immigration" (4) arrested by metal anchored in stone (258-59). If I Do Not Come to You by Chance is a novel in which characters' attempts to demarcate an exclusive community of ethical obligation are unsettled by the transnational address of its form, Open City arrives at a similar crossing from the opposite direction. The spatio-temporal imaginary of each is defined by the intersection of these contradictory patterns.

Nwaubani's and Cole's novels thus demonstrate the entanglement of multiple, overlapping, and frequently competing models of spatio-temporal imagination. I Do Not Come to You by Chance focuses on its characters' attempts to inscribe a form of territorial fixity, demarcating the difference between "inside" and "outside" and constructing historical narratives to explain how Nigerians ought to relate to the wider world. It simultaneously reveals the extent to which these inscriptions are conceptually dependent on "the global," as both the ground on which territoriality is inscribed and a structure of address that deconstructs its boundaries. Open City, by contrast, explores the consciousness of a subject who believes himself to have achieved the liberation of ungrounded (non)belonging, focusing on the patterns of movement and change that constitute the sedimented historicity of his urban locale. The novel's psychoanalytic denouement undoes this celebration of cosmopolitanism, betraying the existence of forms of territorial and historical fixity irreducible to Julius's fetishization of flow. Cooppan expresses this pattern of mutual entanglement and ambivalence when, apropos of Derrida, she observes that " $[t]$ o choose not to live with the ghost of the national, to believe one might, like the ostrich with its head in the sand, banish something by refusing to see or name it is tantamount ... to refusing to live in the world. The nation, in this sense, is the world" (30). The point of my comparison of Nwaubani and Cole is thus not simply to reveal the existence of such a deconstructive operation or to show how attempts to banish either the global or the national ultimately collapse as the repressed returns. Rather, my analyses of I Do Not Come to You by Chance and Open City reveal how tensions between competing modes of spatio-temporal conceptualization function both as thematic elements of the texts and as their implicit ideological substrates. The manner in which each narrative grounds itself in history and territoriality is fundamental to its signification. Had this essay examined any of the other available examples of recent novels that explore nontraditional settings, it would have arrived at a distinctive analysis-such is the complexity of the spatio-temporal imaginary.

My intention has not therefore been to claim that the principle concerns of "Third Generation Nigerian Literature" criticism are wrong. The question of 
whether contemporary subjects perceive themselves in terms of continuity or a break with the past, located within territorial communities or mobile across borders, are clearly issues of importance to texts like Nwaubani's and Cole's. My argument is rather that to approach these questions from an either/or perspective is to oversimplify them and to occlude the extent to which such narratives possess multiple and ambivalent ways of locating themselves in time and space and of linking those practices of placement to ethical norms. These novels offer a multitude of historicizing perspectives that have the potential to supplement the generational-national framework structuring the dominant literary critical approach to such texts.

I therefore suggest that these novels pose a challenge for critical analysis, demanding that it interrogate the frameworks through which it locates texts in time and space. Would it be possible to find a way to narrate literary history with a similar degree of nuance or ambivalence as that possessed by these contemporary novels? What would it look like for analysis of "Third Generation Nigerian Literature" to place the categories of "generation" and "nation" —not to mention "literature" - under question and to try to explore this corpus from a perspective attuned to the interlocking patterns of spatial and temporal positioning that permeate postcolonial writing? What kind of narratives could we produce if we did not locate each novel in a spatio-temporal place defined by its "here" and "now" of production and address, but rather traced the entanglement of times and territories that constitute it, as much as they constitute the ambivalent self-positioning of characters like Kingsley and Julius? One place to begin might be to disaggregate the spatial and temporal registers of analysis that, as I showed above, are frequently fused in criticism of "Third Generation Nigerian Literature." Whatever the result, I suggest that the challenge posed by such novels-to imagine space and time differently-offers a path for enriching analysis of this corpus, expanding the perspectives offered by existing scholarship and promising new insights into this developing field.

\section{NOTES}

1. Another significant theoretical source for this view is Bhabha's The Location of Culture.

2. This is an example of the temporal paradox intrinsic to the logical of mimicry, as outlined by Bhabha in "Of Mimicry and Man" (The Location of Culture 85-92).

3. I would like to thank Dr. Glenn Odom for clarifying the etymology and connotations of this word for me.

4. I would like to thank Research in African Literature's anonymous reviewer for pointing out this implication of Kingsley's use of racist language.

\section{WORKS CITED}

Achebe, Chinua. “The Writer and His Community." Hopes and Impediments. By Achebe London: Heinemann, 1984. 32-41. Print.

Adéèkó, Adélékè. "Power Shift: America in the New Nigerian Imagination." The Global South 2.2 (2008): 10-30. Print. 
Adesanmi, Pius, and Chris Dunton. "Introduction: Everything Good Is Raining: Provisional Notes on the Nigerian Novel of the Third Generation." Research in African Literatures 39.2 (2008): vii-xii. Print.

. "Nigeria's Third Generation Writing: Historiography and Preliminary Theoretical Considerations." English in Africa 32.1 (2005): 7-19. Print.

Anderson, Benedict. Imagined Communities: Reflections on the Origin and Spread of Nationalism. London: Verso, 1983. Print.

Baucom, Ian. Specters of the Atlantic: Finance Capital, Slavery, and the Philosophy of History. Durham: Duke UP, 2005. Print.

Benjamin, Walter. "Theses on the Philosophy of History." Illuminations. Ed. Hannah Arendt. London: Collins, 1973. 253-64. Print.

Bhabha, Homi. The Location of Culture. London; New York: Routledge, 1994. Print.

Black, Shameem. Fiction across Borders: Imagining the Lives of Others in Late TwentiethCentury Novels. New York: Columbia UP, 2010. Print.

Cole, Teju. Open City. London: Faber and Faber, 2011. Print.

Cooppan, Vilashini. Worlds Within: National Narratives and Global Connections in Postcolonial Writing. Stanford: Stanford UP, 2009. Print.

Eze, Chielozona. "Cosmopolitan Solidarity: Negotiating Transculturality in Contemporary Nigerian Novels." English in Africa 32.1 (2005): 99-112. Print.

Hannan, Jim. “Open City.” World Literature Today 85.4 (2011): 59-60. Print.

Hawley, John C. "Biafra as Heritage and Symbol: Adichie, Mbachu, and Iweala." Research in African Literatures 39.2 (2008): 15-26. Print.

Hewett, Heather. "Coming of Age: Chimamanda Ngozi Adichie and the Voice of the Third Generation." English in Africa 32.1 (2005): 73-84. Print.

Hron, Madelaine. "Ora na-azu nwa: The Figure of the Child in Third-Generation Nigerian Novels." Research in African Literatures 39.2 (2008): 27-48. Print.

Jameson, Fredric. The Political Unconscious: Narrative as a Socially Symbolic Act. London: Methuen, 1981. Print.

Julien, Eileen. “The Extroverted African Novel." The Novel: Volume 1: History, Geography, and Culture. Ed. Franco Moretti. Princeton: Princeton UP, 2006. 667-700. Print.

Krishnan, Madhu. "Biafra and the Aesthetics of Closure in the Third Generation Nigerian Novel." Rupkatha 2.2 (2010): 185-95. Print.

Nwakanma, Obi. "Metonymic Eruptions: Igbo Novelists, the Narrative of the Nation, and New Developments in the Contemporary Nigerian Novel." Research in African Literatures 38.2 (2008): 1-14. Print.

Nwaubani, Adaobi Tricia. I Do Not Come to You by Chance. London: Phoenix, 2009. Print.

Ouma, Christopher E. W. "Childhood(s) in Purple Hibiscus." English Academy Review: Southern African Journal of English Studies 26.2 (2009): 48-59. Print.

Pagden, Anthony. "Stoicism, Cosmopolitanism, and the Legacy of European Imperialism." Constellations 7.1 (2000): 3-22. Print.

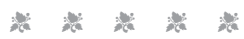


Copyright of Research in African Literatures is the property of Indiana University Press and its content may not be copied or emailed to multiple sites or posted to a listserv without the copyright holder's express written permission. However, users may print, download, or email articles for individual use. 